\title{
Silica-Based Nanocoating Doped by Layered Double Hydroxides to Enhance the Paperboard Barrier Properties
}

\author{
Vânia M. Dias', Alena Kuznetsova², João Tedim², Aleksey A. Yaremchenko², \\ Mikhail L. Zheludkevich², Inês Portugal'1, Dmitry V. Evtuguin 1* \\ ${ }^{1} \mathrm{CICECO}$ /Department of Chemistry, University of Aveiro, Aveiro, Portugal \\ ${ }^{2} \mathrm{CICECO} /$ Department of Materials and Ceramic Engineering, University of Aveiro, Aveiro, Portugal \\ Email: *dmitrye@ua.pt
}

Received 8 September 2015; accepted 5 December 2015; published 8 December 2015

Copyright (C) 2015 by authors and Scientific Research Publishing Inc.

This work is licensed under the Creative Commons Attribution International License (CC BY).

http://creativecommons.org/licenses/by/4.0/

(c) ()

\section{Abstract}

Paperboard is an environment-friendly multi-layer material widely used for packaging applications. However, for food packaging paperboard lacks essential barrier properties towards oxygen and water vapor. Conventional solutions to enhance these barrier properties (e.g. paperboard film coating with synthetic polymers) require special manufacturing facilities and difficult the end-oflife disposal and recycling of the paperboard. Paperboard coating with silica-based formulations is an eco-friendly alternative hereby disclosed. Silica-nanocoatings were prepared by sol-gel synthesis, with or without the addition of $\mathrm{Zn}(2)-\mathrm{Al}^{-\mathrm{NO}_{3}}$ layered double hydroxides (LDHs), and applied on the surface ( $\mathrm{ca} 2 \mathrm{~g} / \mathrm{m}^{2}$ ) of industrial paperboard samples by a roll-to-roll technique. The physicochemical features of silica-nanocoatings were studied by FTIR-ATR, SEM/EDS, XRD analysis and surface energy measurements. The barrier properties of uncoated and silica-coated paperboard were accessed by water vapor transmission rate (WVTR) and oxygen permeability (Joz) measurements. The best barrier results were obtained for paperboard coated with a mixture of tetraethoxysilane (TEOS) and 3-aminopropyltriethoxysilane (APTES), with and without the incorporation of LDHs.

\section{Keywords}

Paperboard, Silica-Based Formulations, Layered Double Hydroxides, Sol-Gel Synthesis, Barrier Properties

\footnotetext{
${ }^{*}$ Corresponding author.

How to cite this paper: Dias, V.M., Kuznetsova, A., Tedim, J., Yaremchenko, A.A., Zheludkevich, M.L., Portugal, I. and Evtuguin, D.V. (2015) Silica-Based Nanocoating Doped by Layered Double Hydroxides to Enhance the Paperboard Barrier Properties. World Journal of Nano Science and Engineering, 5, 126-139. http://dx.doi.org/10.4236/wjnse.2015.54015
} 


\section{Introduction}

Paperboard is a thick paper-based multi-layer material with numerous applications due to its structural stability, lightweight, printable surface, attractive shelf-display and ease of recovery for recycling or end-of-life disposal. However, in comparison with traditional glass and plastic containers paperboard is unsuitable for some foodpackaging applications due to poorer barrier protection against grease, water vapor, oxygen, odors and other substances. Conventional solutions to improve these barrier properties include paperboard wax impregnation or surface coating with petroleum-derived polymer films [1]-[4]. Since both strategies reduce the recyclability and biodegradability features of paperboard in recent years several biopolymers (e.g. starch, cellulose, chitosan, pectin, xylan, isolated soy protein, pullulan among others) have been screened as alternative sustainable coatings for packaging applications [5]-[11]. In addition, nano-sized fillers such as silicate, titanium dioxide and clays, can be added to reinforce the mechanical, thermal and barrier properties of the biopolymers [6] [11]. Alternatively, inorganic nanoparticles can be synthesized in situ in the matrix of the biopolymer, thus forming organic-inorganic hybrid coatings [10]-[12].

The sol-gel process is widely used to produce high purity organic-inorganic composite materials (derived from metals, glass, and ceramics, among others) with excellent mechanical strength and thermal/chemical stability [13]-[15]. The method involves a series of hydrolysis and polycondensation reactions of organometallic precursors (metal alkoxides) that generate nanoparticles randomly dispersed in a polymeric matrix [16]-[18]. Solgel techniques have been used in paper-science for conservation of historic documents, to enhance paper printing quality, and to improve the hydrophobicity of paper [2]. In fact, it has been revealed that silica nanoparticles dispersed on a paper surface form an impermeable interface between a three-dimensional silica network and cellulose fibres [16]-[19]. Moreover, the hydrophobicity of silica-modified surfaces can be enhanced by the incorporation of long-chain aliphatic groupsin the silica network, for example by using a main silica precursor (e.g. tetraethoxysilane) mixed with a secondary organically modified alkoxysilane [19]-[23]. In particular, the use of alkoxysilane bearing amine groups enables the anchoring of specific substances (e.g. catalytic species, sensors or scavengers) that extend the range of application of cellulose-based materials [24] [25].

Layered double hydroxides (LDHs) are plate-like materials possessing high aspect-ratio and ion-exchange capacity [26]-[28]. The incorporation of LDHs in polymeric matrices has high potential to enhance the polymer's barrier properties (the high aspect-ratio increases the length and tortuosity of the diffusion path) without sacrificing the inherent processability and mechanical properties of the pure polymer [10] [26] [27] [29]. The structure of LDHs is based on the brucite structure $\left(\mathrm{Mg}(\mathrm{OH})_{2}\right)$, where some $\mathrm{Mg}^{2+}$ cations are partially substituted by trivalent cations inducing a net positive charge in the hydroxide sheets, balanced by the presence of exchangeable anions and water molecules in the interlayer galleries [26] [29]. The anion-exchange capacity of LDHs, allied to the high aspect ratio and good interfacial interactions with polymer matrices are very appealing for diverse applications such as corrosion protection coatings [27] [30] and polymeric-nanocomposites for food packaging materials [28] [31]. Nevertheless the benefits of LDHs materials for the modification of paperboard packaging materials have not been reported before.

The main goal of this work was to study the impact of silica-based nanocoating, with and without the incorporation of LDHs, on the water vapor and oxygen barrier properties of paperboard.

\section{Materials and Methods}

\subsection{Materials}

Industrial samples of paperboard (210 g/m² and $0.29-0.30 \mathrm{~mm}$ thickness) with a conventional surface treatment applied on the front side (30 - $35 \mathrm{~g} / \mathrm{m}^{2}$ of a slurry of $\mathrm{CaCO}_{3}$ and $\mathrm{Al}_{2} \mathrm{O}_{3}$ particles mixed in a synthetic resin emulsion) were supplied by Prado Karton S.A. (Tomar-Portugal). Hereafter this material will be designated as "uncoated" paperboard.

Silica precursors namely tetraethoxysilane (TEOS), diethoxydimethylsilane (DEDMS), 3-aminopropyltriethoxysilane (APTES), and octyltriethoxysilane (OTES) all with 96\% - 98\% purity, nitric acid (HNO 3 , p.a. 65\% grade) and a low-molecular-weight grade polyethylene glycol (PEG-400) were supplied by Sigma-Aldrich Chem. Co. Precipitated calcium carbonate (PCC) was supplied by the industrial group Portucel-Soporcel (Portugal). Zinc nitrate hexahydrate $\left(\mathrm{Zn}\left(\mathrm{NO}_{3}\right)_{2} \cdot 6 \mathrm{H}_{2} \mathrm{O}, \geq 99 \%\right)$, aluminum nitrate nonahydrate $\left(\mathrm{Al}\left(\mathrm{NO}_{3}\right)_{3} \cdot 9 \mathrm{H}_{2} \mathrm{O}\right.$, $\geq 98.5 \%)$, sodium hydroxide $(\mathrm{NaOH}, \geq 98 \%)$ and sodium nitrate $\left(\mathrm{NaNO}_{3}, \geq 99.5 \%\right)$ were supplied by Sig- 
ma-Aldrich Chem. Co. and used as received for the synthesis of LDHs.

\subsection{Preparation of Silica-Based Formulations and Paperboard Coating}

Silica-based formulations were prepared by sol-gel synthesis [17] [18] using a mineral acid catalyst $\left(\mathrm{HNO}_{3}\right)$ for the hydrolysis of TEOS at pH 1.2-Equation (1). Typically, a mixture of TEOS (0.5 - 1.0 mol), water (0.5 - 2.0 $\mathrm{mol}), \mathrm{HNO}_{3}(50-300 \mu \mathrm{l})$ and PEG-400 $(250-500 \mu \mathrm{l})$ was allowed to react at room temperature $\left(\sim 20^{\circ} \mathrm{C}\right)$ under mechanical stirring (250 rpm) during $40 \mathrm{~min}$. Afterwards, PCC (30 - $50 \mathrm{mg}$ ) was added to raise the pH above the isoelectric point of silica $(\mathrm{pH} 3-4)$ in order to promote the condensation reactions-Equation (2). Some formulations were prepared in a similar way but using TEOS (95\% v/v) and a secondary silica precursor (5\% $\mathrm{v} / \mathrm{v}$ ) such as DEDMS, APTES or OTES in the hydrolysis step.

$$
\begin{gathered}
\mathrm{Si}\left(\mathrm{OC}_{2} \mathrm{H}_{5}\right)_{4}+\mathrm{H}_{2} \mathrm{O} \rightarrow \mathrm{Si}\left(\mathrm{OC}_{2} \mathrm{H}_{5}\right)_{3}(\mathrm{OH})+\mathrm{C}_{2} \mathrm{H}_{5} \mathrm{OH} \\
y \mathrm{Si}\left(\mathrm{OC}_{2} \mathrm{H}_{5}\right)_{3}(\mathrm{OH}) \rightarrow\left(\mathrm{OC}_{2} \mathrm{H}_{5}\right)_{3} \mathrm{Si}-\left[-\mathrm{O}-\mathrm{Si}\left(\mathrm{OC}_{2} \mathrm{H}_{5}\right)_{2}(\mathrm{OH})\right]_{n}+n \mathrm{C}_{2} \mathrm{H}_{5} \mathrm{OH}
\end{gathered}
$$

Silica formulations were applied on the front side (treated surface) of the "uncoated” paperboard surface by roll-to-roll technique using a Mathis LAB reverse roll coater type RRC-BW $350 \mathrm{~mm}$ pilot size-press, at fixed coating speed $(20 \mathrm{~m} / \mathrm{min})$. The distance between the cylinders was adjusted to load a silica formulation on the paperboard surface within the range $2-3 \mathrm{~g} / \mathrm{m}^{2}$. Coatings were cured by infrared-heating (ca. $105^{\circ} \mathrm{C}, 5 \mathrm{~min}$ ).

\subsection{Preparation of Silica-Based Formulations Containing LDHs}

$\mathrm{Zn}-\mathrm{Al}$ layered double hydroxides intercalated with nitrates(Zn(2)-Al- $\mathrm{NO}_{3} \mathrm{LDHs}$ ) were synthesized by the coprecipitation method [30] using decarbonized (boiled and cooled under a flow of nitrogen gas) distilled water in the preparation of solutions.A mixed solution of zinc/aluminum nitrate $\left(\mathrm{Zn}^{2+} 0.05 \mathrm{M}, \mathrm{Al}^{3+} 0.025 \mathrm{M}\right)$ was addeddropwise to an aqueous solution of $\mathrm{NaNO}_{3}(1.5 \mathrm{M})$ under vigorous stirring and nitrogen atmosphere, at $\mathrm{pH} 9$ 10 (controlled by the addition of an aqueous solution of $\mathrm{NaOH}(2.0 \mathrm{M})$ ). At the end of the reaction the resulting suspension was treated hydrothermally $\left(100^{\circ} \mathrm{C}\right.$ during 4 hours) to promote crystal growth. After cooling down to room temperature, LDHs crystals were recovered by centrifugation (10000 r.p.m., 5 min), washed several times with decarbonized distilled water and stored in a closed container in the form of a slurry.

When required, LDHs were added to the silica-based formulations immediately after the condensation reaction and applied on the paperboard surface as previously described (2.2).

\subsection{Analyses of Paperboard Surfaces}

Contact angles $(\theta)$ of uncoated and coated paperboard surfaces were measured at room temperature $\left(23^{\circ} \mathrm{C}-25^{\circ} \mathrm{C}\right)$ on a DataPhysics Instrument OCA20, using the sessile drop method (drop volume ca $2.0 \mu \mathrm{l}$ ) and three different probe-liquids namely diiodomethane (Aldrich, 99\% purity GC), formamide (Sigma, 99\% purity GC) and distilled water (MilliQ grade).

The Owens-Wendt-Rable-Kaeble (OWRK) model [32] was used to assess the total surface energy $\left(\gamma_{s}\right)$ of paperboard surfaces, and the corresponding polar $\left(\gamma_{s}^{p}\right)$ and dispersive $\left(\gamma_{s}^{d}\right)$ components, using measured contact angles $(\theta)$, liquid-probe surface tension data (Table 1) and Equations (3) and (4) [18] [32] [33].

$$
\begin{gathered}
\gamma_{s}=\gamma_{s}^{d}+\gamma_{s}^{p} \\
((1+\cos \theta) / 2) \times\left(\gamma_{l} /\left(\gamma_{l}^{d}\right)^{1 / 2}\right)=\left(\gamma_{s}^{p}\right)^{1 / 2} \times\left(\gamma_{l}^{p} / \gamma_{l}^{d}\right)^{1 / 2}+\left(\gamma_{s}^{d}\right)^{1 / 2}
\end{gathered}
$$

where, $\gamma_{l}$ is the total surface tension of the liquid, and $\gamma_{l}^{p}$ and $\gamma_{l}^{d}$ are the polar and dispersive components of the surface tension, respectively. Plotting the right-hand-side of Equation (4) as a function of $\left(\gamma_{1}^{p} / \gamma_{1}^{d}\right)^{1 / 2}$ enables the calculation of $\gamma_{s}^{p}$ and $\gamma_{s}^{d}$ from the parameters of the linear regression (Equation (4)). The wetting envelopes of the paperboard surfaces were obtained by representing $\gamma_{s}^{p}$ versus $\gamma_{s}^{d}$ at a fixed contact angle $(\theta$ $\left.=90^{\circ}\right)[34]$.

Silica-coated paperboard samples were characterized by Fourier Transform Infra-red spectroscopy with Attenuated Total Reflectance (FTIR_ATR) analysis with the spectra being recorded in absorbance mode in the range $4000-400 \mathrm{~cm}^{-1}$, co-adding 200 scans at $8 \mathrm{~cm}^{-1}$ resolution (Mattson FT-IR spectrometer Model 7000 equipped 
Table 1. Surface tension and corresponding polar and dispersive components of the standard liquids used for surface energy calculations [32] [33].

\begin{tabular}{cccc}
\hline Liquid & Surface tension, $\gamma_{l}\left(\mathrm{~mJ} / \mathrm{m}^{2}\right)$ & Polar component, $\gamma_{i}^{p}\left(\mathrm{~mJ} / \mathrm{m}^{2}\right)$ & Dispersive component, $\gamma_{1}^{d}\left(\mathrm{~mJ} / \mathrm{m}^{2}\right)$ \\
\hline Water & 72.8 & 51.0 & 21.8 \\
Formamide & 58.0 & 20.4 & 37.6 \\
Diiodomethane & 50.8 & 2.3 & 48.5 \\
\hline
\end{tabular}

with Golden Gate diamond ATR cell). Penetration of the silica formulations was evaluated by Scanning Electron Microscopy/Energy Dispersive Spectroscopy (SEM/EDS) analysis (SEM Hitachi SU-70 microscope operating at $15 \mathrm{kV}$; EDS Brucker Quantax 400 detector) of transversal cuts of paperboard.

The structure of LDHs in the silica formulations was analyzed by X-ray diffraction (XRD) using a Philips X'Pert MPD diffractometer (Bragg-Brentano geometry, $\mathrm{Cu} \mathrm{K} \alpha$ radiation, and the exposition corresponded to $5 \mathrm{~s}$ per step of $0.02^{\circ}$ over the angular range $4<2 \theta<65^{\circ}$ ).

Physical and mechanical properties of paperboard samples were evaluated by standardized tests: tensile strength (N/m) was determined according to NP EN ISO 1924-2 and used to evaluate the Tensile Index (i.e. tensile strength divided by grammage $\left(\mathrm{g} / \mathrm{m}^{2}\right)$ ); burst strength $(\mathrm{kPa})$ was determined by NP EN ISO 2758; Bendtsen roughness $\left(\mathrm{cm}^{3} / \mathrm{min}\right)$ and porosity were both determined following NP EN ISO 8791; air permeation was measured by the Gurley method (NP 795 ISO 5636-5).

\subsection{Paperboard Barrier Properties}

Water vapor barrier properties of paperboard surfaces were measured in triplicate, for each sample, using standard procedures (ASTM E96-95) and the "desiccant method" [35]. Accordingly, circular paperboard samples were sealed to the open mouth of test-cups (area $19.6 \mathrm{~cm}^{2}$; internal depth $2.0 \mathrm{~cm}$ ) containing a desiccant, namely anhydrous calcium chloride $(0 \%$ relative humidity $(\mathrm{RH}))$ previously dried at $200^{\circ} \mathrm{C}(2 \mathrm{~h})$, and weighed. Afterwards, the sealed test-cups were placed in a test chamber with forced air circulation, at $26^{\circ} \mathrm{C} \pm 1{ }^{\circ} \mathrm{C}$ and $52 \% \mathrm{RH}$ (obtained with a saturated aqueous solution of magnesium nitrate hexahydrate [35]), and weighed periodically over a three day period. The amount of water transferred through the paperboard sample, i.e. the test-cup weight gain ( $\Delta W=W_{t}-W_{t=0}$ ), along time $(t)$ was used to evaluate the water vapor transmission rate (WVTR, $\mathrm{g} \cdot \mathrm{m}^{-2} \cdot \mathrm{day}^{-1}$ ) from the linear representation of the experimental data, as expressed by Equation (5)

$$
\Delta W=A \times \mathrm{WVTR} \times t
$$

where $A$ is the exposed area of the paperboard sample $\left(19.6 \mathrm{~cm}^{2}\right)$.

Oxygen permeation through uncoated and silica-coated paperboard samples was measured by a proven technique used for the characterization of glass-ceramic and ceramic dense membranes [36]-[38]. The experimental setup comprised one sample holder (alumina tube) and two electrochemical yttrium-stabilized zirconia (YSZ) oxygen sensors. The paperboard sample was hermetically sealed on the top-opening of the alumina tube with cyanoacrylate adhesive. The outside of the paperboard sample was exposed to air while the inner surface was swept by a nitrogen flow $\left(50 \mathrm{~cm}^{3} \cdot \mathrm{min}^{-1}\right.$, with oxygen partial pressure ca. $\left.2 \mathrm{~Pa}\right)$. Oxygen partial pressure in the sweep gas flow at the inlet $\left(P\left(\mathrm{O}_{2}\right)_{\text {in }}\right)$ and outlet $\left(P\left(\mathrm{O}_{2}\right)_{\text {out }}\right)$ of the sample holder under steady-state conditions was determined using YSZ sensors. In the course of experiment, the paperboard sample was at room temperature and under zero total pressure gradients. Specific oxygen permeation fluxes $\left(J_{\mathrm{O}_{2}}, \mathrm{~m}^{3} \cdot \mathrm{m}^{-2} \cdot \mathrm{day}^{-1}\right)$ were calculated using Equation (6)

$$
J_{\mathrm{O}_{2}}=\left(F_{\mathrm{N}_{2}} / S\right) \times\left[P\left(\mathrm{O}_{2}\right)_{\text {out }}-P\left(\mathrm{O}_{2}\right)_{\text {in }}\right] / P
$$

where $F_{N_{2}}$ is the inlet nitrogen flow rate $\left(50 \mathrm{~cm}^{3} \cdot \mathrm{min}^{-1}\right), P$ is the total pressure (Pa) and $S$ is the sample's exposed surface area $\left(0.785 \mathrm{~cm}^{2}\right)$.

\section{Results and Discussion}

\subsection{Paperboard Coating with Silica-Based Formulations}

Uncoated paperboard was supplied with a conventional surface treatment applied on the front side to improve 
surface smoothness and opacity (the $\mathrm{CaCO}_{3}$ and $\mathrm{Al}_{2} \mathrm{O}_{3}$ white particles mixed in a synthetic resin mask the darker internal layers of paperboards). It is presumed that silica based formulations applied in small amounts (2 - 3 $\mathrm{g} / \mathrm{m}^{2}$ ) do not change the general appearance of the paperboard surface, but hopefully improve their barrier properties. This is confirmed by the oxygen and water vapor barrier properties results presented (qualitatively) in Table 2 for paperboard coated with silica formulations prepared using various precursors (alkoxysilanes) with and without the incorporation of LDHs. Moreover, these results indicate that the barrier properties are influenced by the nature of the functional groups introduced in the silica network. By means of example, the TEOS_APTES silica network without (III) and with (IIIa) LDHs is schematically represented in Figure 1.

The SEM-EDS images of uncoated and silica-coated paperboard are presented in Figure 2 to analyze the surface morphology and the penetration of silica (represented in red colour). Uncoated paperboard presents a smooth surface (Figure 2, front side) whereas silica-coated paperboard exhibit some cracks more pronounced for the TEOS_OTES coating (IV)than for the TEOS_DEDMS (II) and TEOS_APTES coating (III) (Figure 2, front side and cross-section) that apparently influence the barrier properties (to be discussed further on). Besides, distribution of silica appears to be more homogeneous for coating (IV) than for coating (II) and (III). In all cases, silica penetrates deep inside the paperboard layers (Figure 2, cross-section) due to the relatively low viscosity of the formulations, even though most part of the silica is retained on the treated surface. The incorporation of

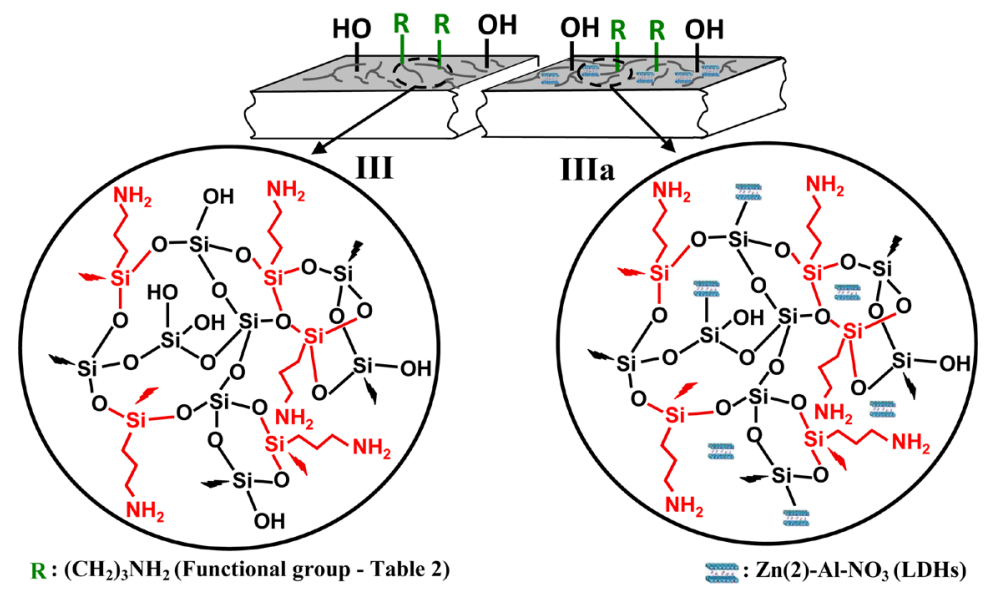

Figure 1. Schematic representation of the silica-network formed on the paperboard surface upon coating with TEOS_APTES formulation with (IIIa) and without (III) incorporation of LDHs.
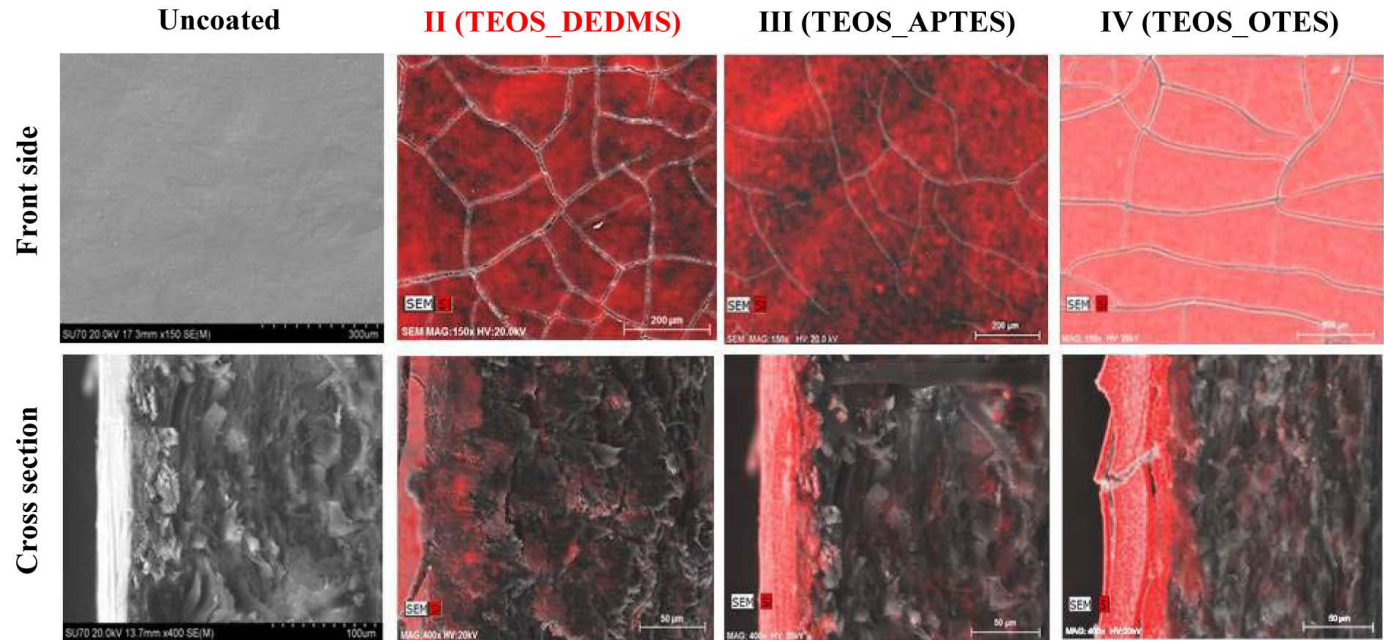

Figure 2. SEM-EDS images (front side and cross section) of paperboard before (uncoated) and after coating with TEOS_DEDMS (II),TEOS_APTES (III) or TEOS_OTES (IV) formulations applied on the front side of the paperboardsurface (located on the left side of the images). 
Table 2. Barrier properties (qualitative) for uncoated and silica coated paperboard.

\begin{tabular}{|c|c|c|c|c|c|}
\hline & & \multicolumn{4}{|c|}{ Barrier property } \\
\hline & & Functional group (R) & Cracks & $\mathrm{H}_{2} \mathrm{O}$ & $\mathrm{O}_{2}$ \\
\hline & Uncoated & ------------ & ------- & + & +++ \\
\hline I & TEOS & \multirow{2}{*}{$-\mathrm{OH}$} & \multirow{2}{*}{+++} & ++ & +++++ \\
\hline Ia & TEOS_LDHs & & & +++ & +++++ \\
\hline II & TEOS_DEMDS & \multirow[b]{2}{*}{$-\mathrm{CH}_{3}$} & \multirow[b]{2}{*}{++} & ++++ & ++++++ \\
\hline IIa & TEOS_DEDMS_LDHs & & & +++++ & +++++ \\
\hline III & TEOS_APTES & \multirow{2}{*}{$-\left(\mathrm{CH}_{2}\right)_{3} \mathrm{NH}_{2}$} & \multirow{2}{*}{+} & ++++ & ++++++ \\
\hline IIIa & TEOS_APTES_LDHs & & & ++++++ & +++++ \\
\hline IV & TEOS_OTES & \multirow{2}{*}{$-\left(\mathrm{C}_{7} \mathrm{H}_{14}\right) \mathrm{CH}_{3}$} & \multirow{2}{*}{++++} & ++++ & ++ \\
\hline IVa & TEOS_OTES_LDHs & & & ++++++ & + \\
\hline
\end{tabular}

LDHs has no significant effect on silica distribution (SEM images are similar with and without LDHs) neither on cracks formed on the paperboard surface (Table 2).

The chemical composition and uniformity of the silica-based coatings was further accessed by FTIR_ATR analysis (Figure 3). In fact, uncoated paperboard presents a sharp band at $1385-1400 \mathrm{~cm}^{-1}$ (assigned to the presence of nitrate anions [39] introduced in the industrial paperboard treatment process) almost absent in the spectra of coated paperboards. Since this technique examines only the surface of the sample one may conclude that paperboard was completely covered by the silica coatings that turn nitrate anions inaccessible towards FTIR-ATR analysis.

The most significant peaks in the spectra of silica-coated paperboards (Figure 3(a)) have been assigned to silanol groups ( $\mathrm{Si}-\mathrm{OH}$ stretching at $950 \mathrm{~cm}^{-1}$ ) and silica oxide moieties (e.g. Si-O-Si bending at $450 \mathrm{~cm}^{-1}$; asymmetric and symmetric Si-O-Si stretching at $1050 \mathrm{~cm}^{-1}$ and $800 \mathrm{~cm}^{-1}$, respectively) thus confirming the occurrence of hydrolysis and condensation reactions of the alkoxysilanes [17] [40]. In addition, the use of silica coprecursors led to the appearance of characteristic small peaks (almost unnoticeable) in the FTIR-ATR spectra. For instance, the small peak at $1265 \mathrm{~cm}^{-1}$ in the spectrum of TEOS_DEDMS (II) is attributed to the presence of $\mathrm{CH}_{3}$ groups [22]; the absorption band at $2930 \mathrm{~cm}^{-1}$ in the TEOS_OTES spectrum (IV) corresponds to the asymmetric stretching vibrations of C-H bonds [21]; in the TEOS_APTES spectrum (III) the band at $1548 \mathrm{~cm}^{-1}$ is attributed to $\mathrm{N}-\mathrm{H}$ vibrations of amino groups and the bands at $2929 \mathrm{~cm}^{-1}$ and $1461 \mathrm{~cm}^{-1}$ are assigned respectively to stretching and bending vibrations of aminopropyl $\mathrm{CH}_{2}$ groups [23] [41].

\subsection{Paperboard Coating with Silica-Based Formulations and LDHs}

$\mathrm{Zn}(2)-\mathrm{Al}-\mathrm{NO}_{3}$ type LDHs are expected to act as barrier promoters when added to silica-coated paperboard due to the high anion-exchange capacity of these nanomaterials [27]. The incorporation of LDHs in the silica coating without their degradation or loss of structural integrity was examined by FTIR-ATR and XRD analysis.

The FTIR-ATR spectra of silica-coated paperboard without and with LDHs (Figure 3(a) and Figure 3(b), respectively) are quite similar except for the peak in the region $1350-1385 \mathrm{~cm}^{-1}$, superposed with a shoulder near $1400 \mathrm{~cm}^{-1}$. The presence of these bands, assigned to symmetric and asymmetric stretching modes of nitrate anions [30], undoubtedly confirm the incorporation of LDHs in the nanocoating.

The XRD patterns presented in Figure 4 indicate that $\mathrm{Zn}(2)-\mathrm{Al}_{-} \mathrm{NO}_{3} \mathrm{LDHs}$ particles (obtained by co-precipitation) are single-phase materials displaying characteristic reflection peaks at low $2 \theta$ angles $\approx 10^{\circ}, 20^{\circ}$ and $30^{\circ}$ (ascribed to (00l) reflections) and a basal plane spacing ( $d$, calculated from the position of $(00 l)$ reflections) in the range $0.89-0.90 \mathrm{~nm}$. These results are in agreement with literature data for $\mathrm{Zn}(2)-\mathrm{Al} \mathrm{LDHs}$ intercalated with $\mathrm{NO}_{3}^{-}$[30] [42]. Furthermore, the fundamental reflections associated with LDHs are still visible when LDHs are incorporated into silica formulations, thereby confirming the successful preparation of silica nanocoating with LDHs particles. 


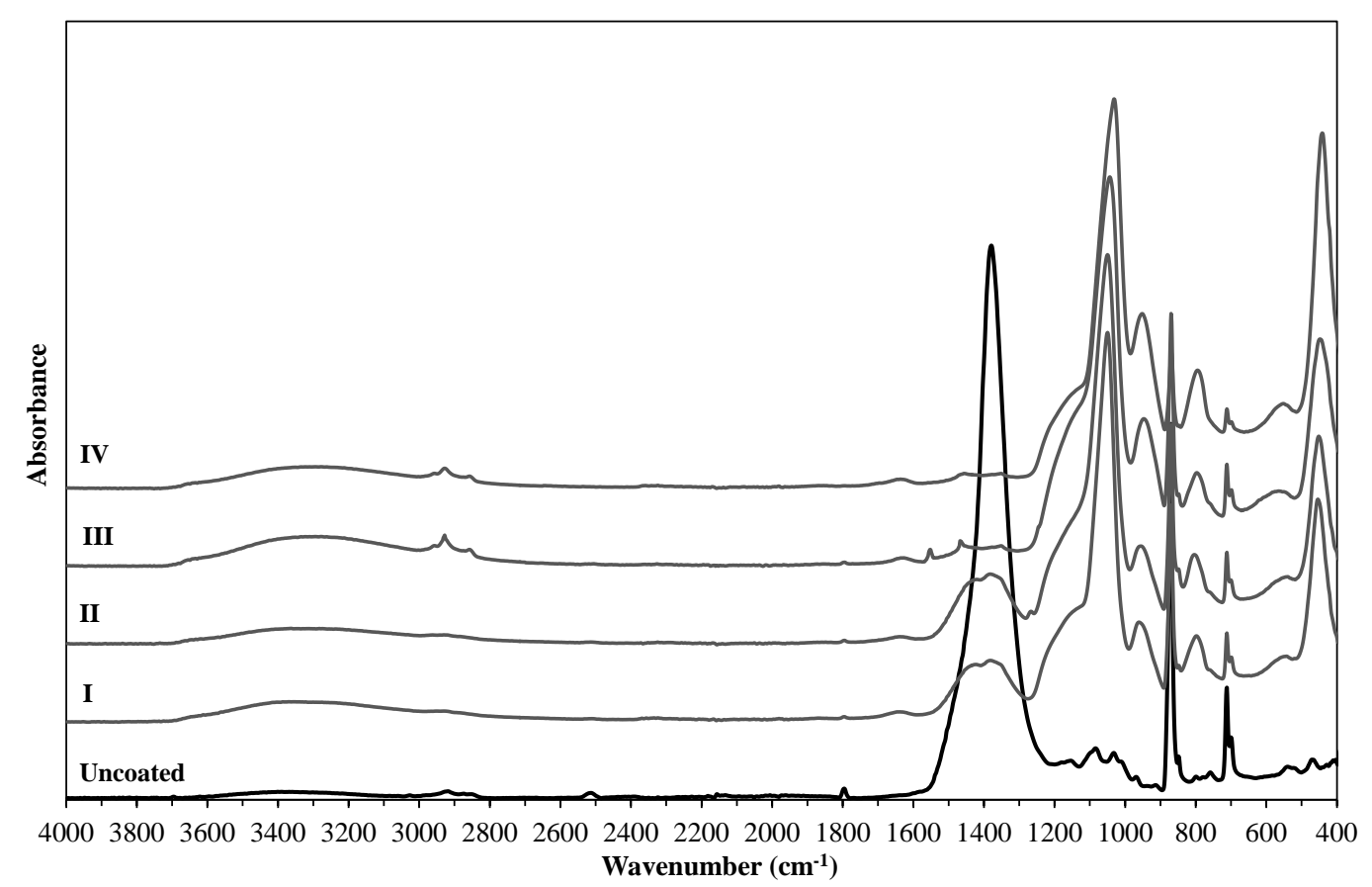

(a)

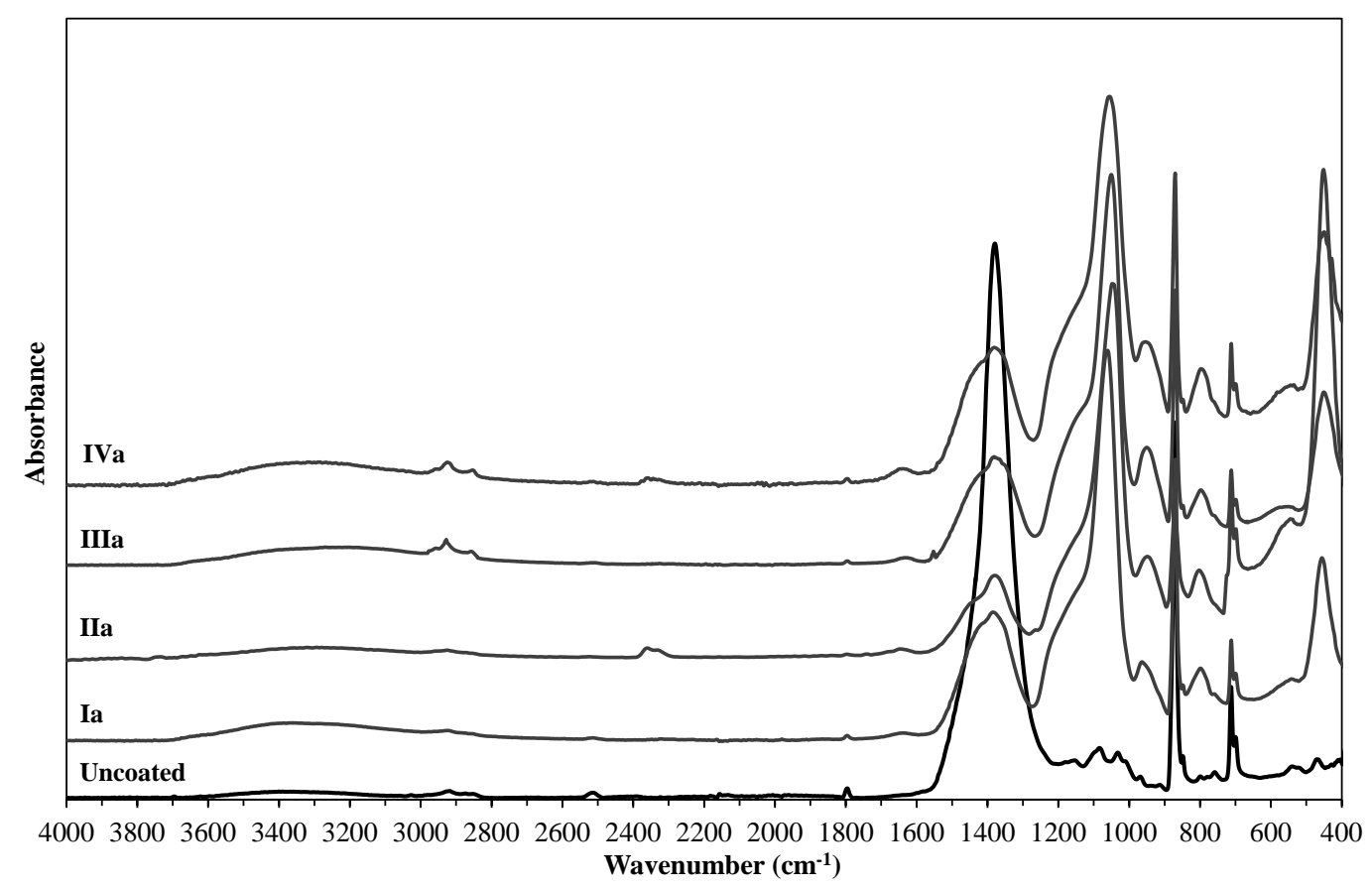

(b)

Figure 3. FTIR-ATR spectra of paperboard before (uncoated) and after coating with several silica based formulations without (a) and with (b) incorportation of LDHs.

\subsection{Physical and Mechanical Properties of Silica-Coated Paperboard}

The physical and mechanical properties of industrial paperboard uncoated and coated with various silica-based formulations (without (I to IV) and with (Ia to IVa) LDHs) are presented in Table 3. The results reveal that silica coating (I to IV) consistently improves paperboard properties such as tensile index (indicative of fibre 
Table 3. Physical and mechanical properties and barrier properties of industrial paperboard before (uncoated) and after coating with various silica based formulations with (Ia to IVa) and without (I to IV) incorportation of LDHs.

\begin{tabular}{|c|c|c|c|c|c|c|}
\hline & Load $\left(\mathrm{g} / \mathrm{m}^{2}\right)$ & $\begin{array}{l}\text { Tensile index } \\
(\mathrm{Nm} / \mathrm{g})\end{array}$ & $\begin{array}{l}\text { Bendtsen roughness }{ }^{a} \\
(\mathrm{ml} / \mathrm{min})\end{array}$ & $\begin{array}{l}\text { Burst strength } \\
(\mathrm{kPa})\end{array}$ & $\begin{array}{c}\text { WVTR } \\
\left(\mathrm{g} \cdot \mathrm{m}^{-2} \cdot \mathrm{day}^{-1}\right)\end{array}$ & $\begin{array}{c}J_{\mathrm{O} 2} \\
\left(\mathrm{~m}^{3} \cdot \mathrm{m}^{-2} \cdot \text { day }^{-1}\right)\end{array}$ \\
\hline Uncoated & ----- & 65 & 88 & 535 & $549 \pm 21$ & 1.51 \\
\hline I & 2.09 & 66 & 129 & 590 & $300 \pm 5$ & 0.68 \\
\hline Ia & 2.03 & 67 & 118 & 593 & $270 \pm 3$ & 1.04 \\
\hline II & 2.42 & 67 & 145 & 572 & $231 \pm 3$ & 0.56 \\
\hline IIa & 2.14 & 67 & 138 & 606 & $199 \pm 3$ & 0.94 \\
\hline III & 2.05 & 66 & 147 & 582 & $222 \pm 4$ & 0.49 \\
\hline IIIa & 2.15 & 68 & 138 & 593 & $132 \pm 3$ & 0.78 \\
\hline IV & 2.07 & 66 & 204 & 569 & $226 \pm 4$ & 2.58 \\
\hline IVa & 2.10 & 68 & 216 & 613 & $131 \pm 3$ & 1.92 \\
\hline
\end{tabular}

(a) (i.e. the airflow leaking between the tested surface and the head of the equipment).

strength) and burst strength (indicative of pressure tolerance before rupture). The addition of LDHs (Ia to IVa) causes a further increase in burst strength and tensile index (except for TEOS_DEDMS_LDHs coating (IIa)). Overall, the basic mechanical properties of paperboard are maintained or improved by silica nanocoating, especially when LDHs are incorporated in the silica formulations.

Surface roughness (Bendtsen roughness i.e. the airflow $(\mathrm{ml} / \mathrm{min}$ ) leaking between the tested surface and the head of the equipment) increases with silica coating and is reduced by the addition of LDHs (except for TEOS_ OTES_LDHs coating (IVa)). Moreover, the nanocoating lowers the porosity of paperboard (measured as Bendtsen porosity i.e. airflow required for air to leak across the paperboard) from $12 \mathrm{ml} / \mathrm{min}$ (uncoated) to $10 \mathrm{ml} / \mathrm{min}$ or lower (silica-coated).

\subsection{Surface Wettability of Silica-Coated Paperboard}

The amount of gas or vapor permeating a solid membrane is affected by the diffusivity and solubility of the permeant in the membrane material. Hence the affinity of water to paperboard surface plays an important role. Uncoated and silica-coated paperboard surfaces were characterized by contact angle measurements to evaluate water affinity by means of the polar and dispersive components of the total surface energy (calculated with the OWRK model [32]). The results presented in Figure 5 reveal that silica coating, the nature of the functional groups incorporated in the silica network and the addition of LDHs have a significant impact on the surface energy parameters, especially on its polar component.

The surface energy of uncoated paperboard $(\sim 32 \mathrm{mN} / \mathrm{m})$ is dominated by its dispersive component. Coating with TEOS-based formulations introduces free hydroxyl groups on the paperboard surface that increase the total surface energy ( $\sim 4 \mathrm{mN} / \mathrm{m})$ and its polar component $(\sim 19 \mathrm{mN} / \mathrm{m})$ and thus confer an undesirable hydrophilic character. To control hydrophilicity alternative formulations were prepared with TEOS $\left(\mathrm{Si}\left(\mathrm{OC}_{2} \mathrm{H}_{5}\right)_{4}\right)$ partially replaced by a secondary silica precursor $(5 \% \mathrm{w} / \mathrm{w})$ bearing different functionalities, as presented in Table 2 (formulations II, III and IV): DEDMS has two methyl groups $\left(\left(\mathrm{CH}_{3}\right)_{2} \mathrm{Si}\left(\mathrm{OC}_{2} \mathrm{H}_{5}\right)_{2}\right)$, APTES has one aminopropyl group $\left(\mathrm{H}_{2} \mathrm{~N}\left(\mathrm{CH}_{2}\right)_{3} \mathrm{Si}\left(\mathrm{OC}_{2} \mathrm{H}_{5}\right)_{3}\right)$ and OTES has one octyl group $\left(\left(\mathrm{C}_{8} \mathrm{H}_{17}\right) \mathrm{Si}\left(\mathrm{OC}_{2} \mathrm{H}_{5}\right)_{3}\right)$. As expected, the paperboard's total surface energy and especially its polar component decreased significantly in comparison with the results obtained for paperboard coated only with TEOS (formulation I) (Figure 5). The total surface energy follows the order I > III > IV > II whereas the polar component follows the order I > III > II > IV. This can be better understood bearing in mind that the replacement of TEOS with OTES (formulation IV) introduces long chain hydrophobic -Si-octyl groups that increase the surface hydrophobicity (lower polar component); the replacement of TEOS with DEDMS (formulation II) reduces the number of free hydroxyl and alkoxy groups on the silica network; the replacement of TEOS with APTES (formulation III) introduces amine groups, which can form hydrogen bonds with water molecules conferring a hydrophilic character to the surface [43].

In general, the polar component of the surface energy is slightly higher for the formulation with LDHs (Ia to 


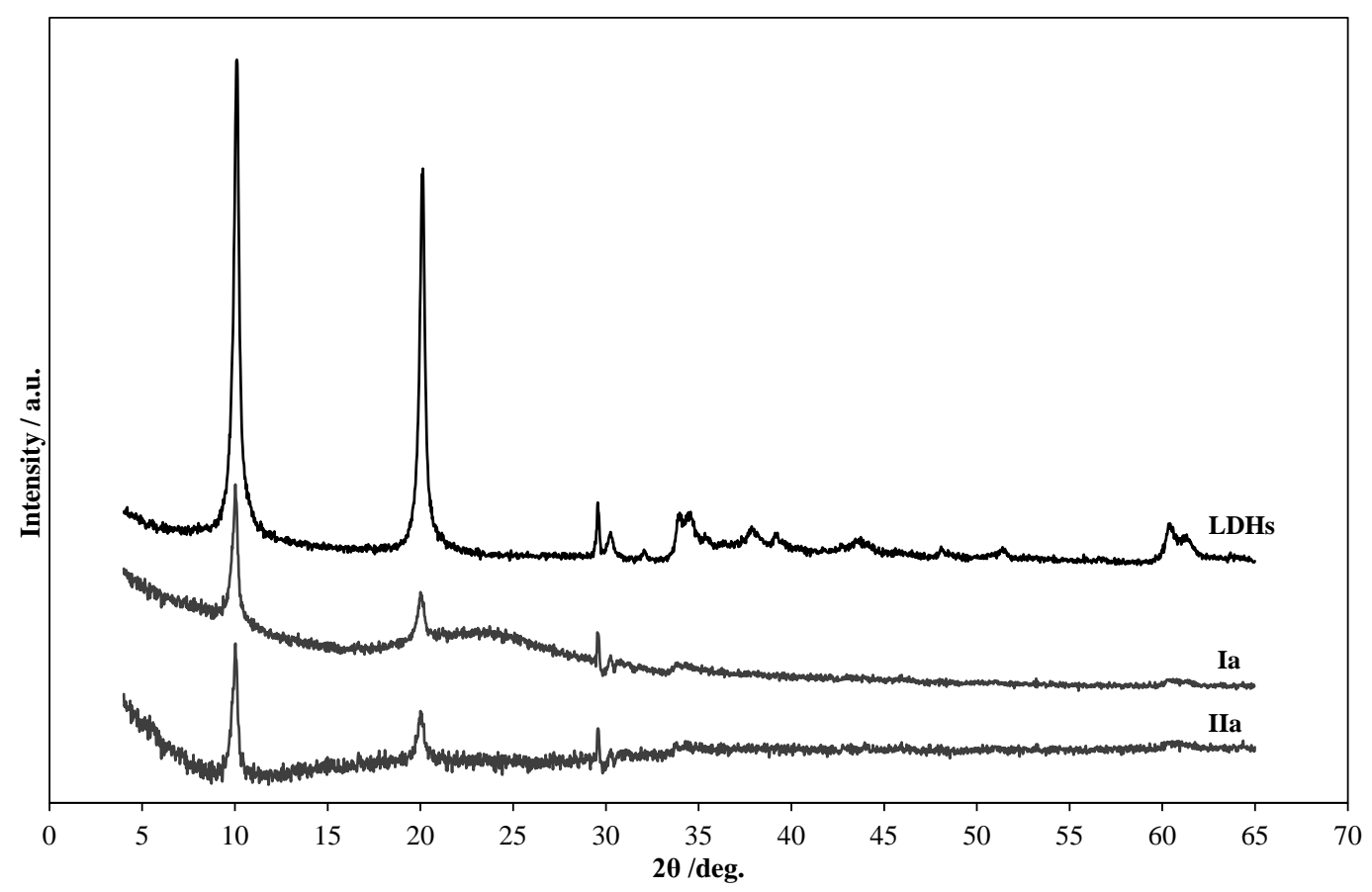

Figure 4. X-ray diffractograms of LDHs and silica formulations (Ia and IIa) containing LDHs (TEOS_LDHs (Ia) and TEOS_DEDMS_LDHs (IIa)).

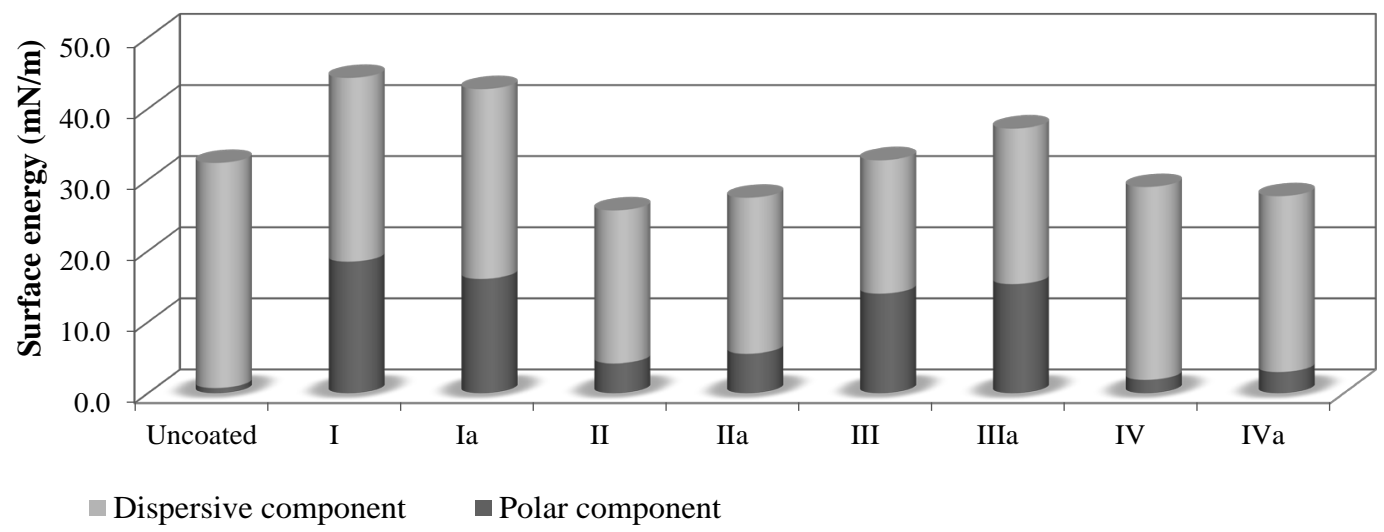

Figure 5. Polar and dispersive components of the total surface energy of paperboard before (uncoated) and after coating with several silica based formulations, without (I to IV) and with (Ia to IVa) incorportation of LDHs.

IVa) in comparison to the formulation without LDHs (I to IV) (Figure 5). This can be explained by the hydrophilic character of $\mathrm{LDH}-\mathrm{NO}_{3}$, which displays capacity to retain water internally, between the layers, and externally, in the hydroxide layers [27].

The polar and dispersive components of the surface energy were used to draw the surface wetting envelopes $\left(\gamma_{l}^{p}\right.$ versus $\gamma_{s}^{d}$ at a fixed contact angle), a very useful tool to predict the contact angle of a particular liquid with the solid surface [34]. The contact angle selected $\left(\theta=90^{\circ}\right)$ describes the frontier situation for wettable $(\theta<$ $90^{\circ}$ ) and non-wettable $\left(\theta>90^{\circ}\right)$ surfaces based on the general contact angle theory of Young [44] [45], i.e. a solid surface is defined as hydrophobic or hydrophilic when the contact angle of a water droplet is larger or smaller than $90^{\circ}$, respectively [44]-[46]. For better visualization of surface wettability the water coordinates are represented by a dark point in Figure 6: when the point is located outside the wetting envelope curve the water contact angle with the surface is greater than $90^{\circ}$, i.e. the surface is non-wettable. Accordingly, the following conclusions 


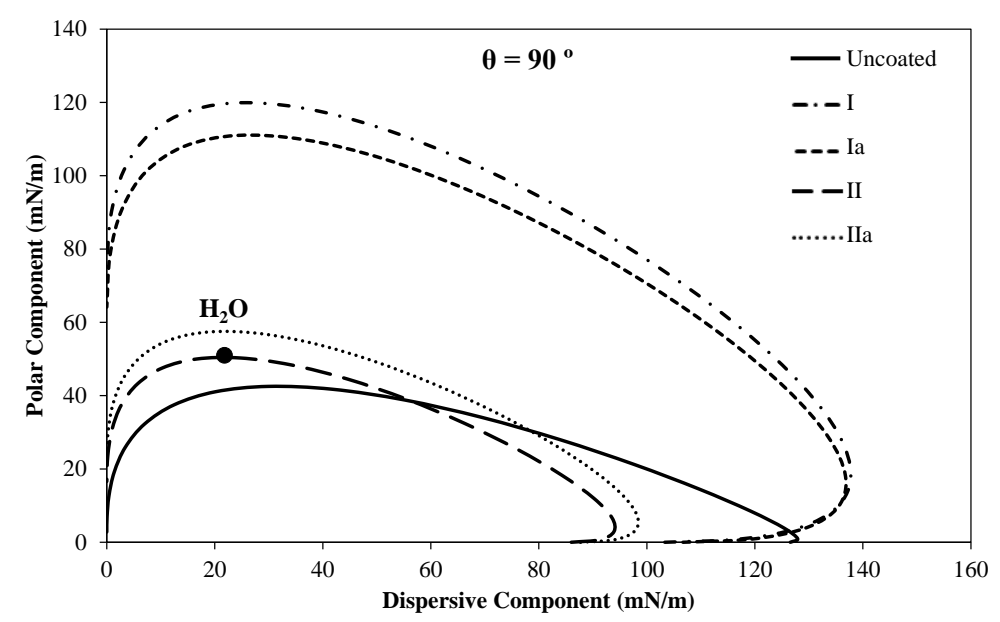

(a)

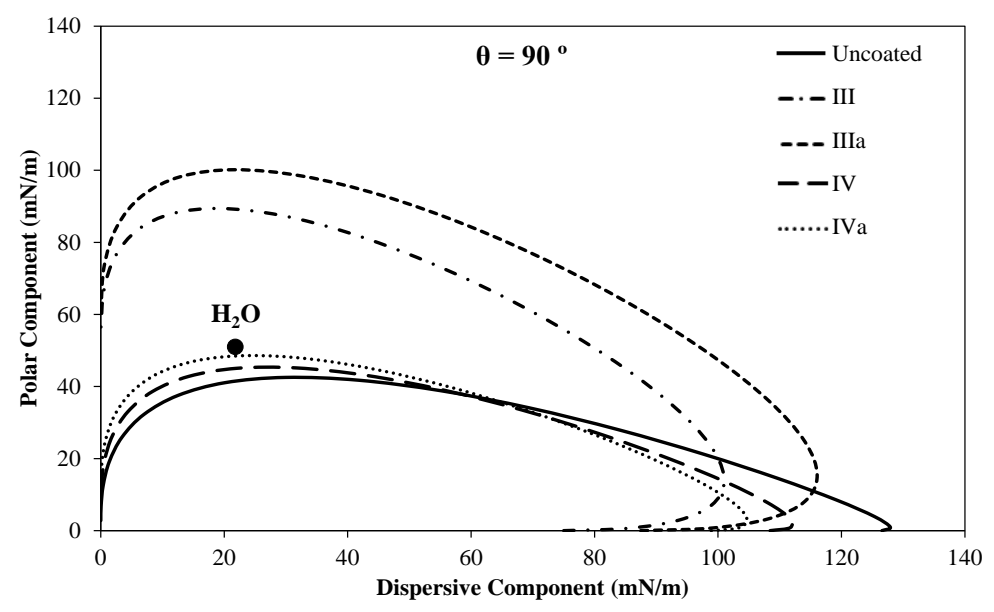

(b)

Figure 6. Wetting envelope at a fixed contact angle $\left(\theta=90^{\circ}\right)$ for paperboard before (uncoated) and after coating with several silica based formulations without (I to IV) and with (Ia to IVa) incorportation of LDHs.

might be drawn from the analysis of the curves presented in Figure 6: wettability of uncoated paperboard is low; paperboard coated only with TEOS (formulation I-Figure 6(a)) presents high wettability (the water point is located far from the $90^{\circ}$ wetting envelope); the partial replacement of TEOS with DEDMS (formulation II-Figure 6(a)) or OTES (formulation IV-Figure 6(b)) reduces wettability due to the lower number of free hydroxyl groups remaining on the surface and because of the long chain -Si-octyl groups introduced by OTES (formulation IV) [20] [21]; the partial replacement of TEOS with APTES (formulation III) creates a wettable surface due to the hydrophilic character conferred by the amine groups [43], as previously discussed. Finally, the incorporation of LDHs imparts an insignificant change in the wettability of paperboard coated with TEOS (formulation Ia-Figure 6(a)) even though wettability increases slightly for the other formulations (IIa-Figure 6(a), IIIa and IVa-Figure 6(b)).

\subsection{Water Vapor and Oxygen Barrier Properties}

Water vapor transmission rate (WVTR) and oxygen permeability $\left(J_{O 2}\right)$ were measured to evaluate the barrier properties of uncoated and silica coated paperboards with and without LDHs. The results are presented qualitatively in Table 2 and quantitatively in Table 3.

WVTR for uncoated paperboard $\left(550 \mathrm{~g} \cdot \mathrm{m}^{-2} \cdot \mathrm{day}^{-1}\right.$ ) was considerably reduced after coating with TEOS (formulation I) ( 45\%) or TEOS mixed with a secondary precursor (formulations II, III or IV) ( 60\%). A further 
reduction ( $10 \%$ to $40 \%)$ is attained by the incorporation of LDHs (formulations Ia to IVa). These results demonstrate the potential of silica nanocoatings to expand the applicability of paperboards in food packaging. However, WVTR values are still below the levels furnished by synthetic polymers in coated paperboards used for food containers $\left(10 \mathrm{~g} \cdot \mathrm{m}^{-2} \cdot \mathrm{day}^{-1}\right)$ [5].

Paperboard coated by non-modified silica (formulation I, TEOS)presents better water vapor barrier properties than uncoated paperboard in spite of the lower water repellence i.e. higher polarity (Figure 5) and wettability (Figure 6(b)) of the coated surface. This apparent controversy can be explained by the formation of an impermeable surface between the three-dimensional silica network and cellulose fibersin the paperboard via strong hydrogen bonding involving the hydroxyl groups of silica and cellulose [16]-[18]. The use of alkoxysilane coprecursors does not disturb the silica network and lowers the concentration of free hydroxyl groups on the surface, thus conferring hydrophobicity to the silica-coated paperboard (formulation (II)—Figure 7). This is corroborated by the surface energy data (Figure 5 and Figure 6) and explains the lower WVTR values of paperboard coated with mixed formulations II, III or IV (Table 3). Incorporation of LDHs in the silica formulations (formulation (IIa) - Figure 7) provides an additional reduction of the WVTR values (formulations Ia to IVa-Table 3) not only because of their ability to retain water molecules in the interlayer region as water scavengers [27] [30] but also because of their high aspect-ratio (flat structure) that increases the length and tortuosity of the diffusion path [29] [47]. A final undesirable aspect that ought to be resolved is the formation of cracks in the paperboard coated surface (SEM images Figure 2 and Table 2) that provide pathways for water vapor diffusion, therefore diminishing the barrier properties.

Silica-based nanocoatings prepared with TEOS alone (formulation (I)-Figure 7) or mixed with a co-precursor such as DEDMS (formulation (II)—Figure 7) or APTES (formulation (III)—Figure 1) enhanced the oxygen barrier properties of paperboard (Table 2 and Table 3). In fact, oxygen permeability of uncoated paperboard $\left(1.51 \mathrm{~m}^{3} \cdot \mathrm{m}^{-2} \cdot\right.$ day $\left.^{-1}\right)$ was reduced by $55 \%, 63 \%$ and $68 \%$ after coating with formulations I, II and III, respectively. This behaviorwas previously discussed and ascribed to the dense and impermeable silica network formed on the paperboard surface (Figure 7) [16]-[18] [48]. Apparently, the nature of the co-precursor has a small effect on oxygen permeability except for formulation IV (TEOS_OTES). Most likely the presence of bulky organic radicals (-Si-octyl groups) in the silica formulation affects adversely the density and physical integrity of the inorganic network as revealed by the SEM analysis. In fact, the front and cross-section images of silica-coated paperboard (Figure 2) show more and deeper cracks for formulation IV (TEOS_OTES) than for formulation II (TEOS_DEDMS) and formulation III (TEOS_APTES) thus explaining the particularly high oxygen permeability rate observed for the first formulation $\left(2.578 \mathrm{~m}^{3} \mathrm{~m}^{-2} \cdot \mathrm{day}^{-1}\right)$ [21] [23] [48]. The incorporation of LDHs has a similar effect decreasing the barrier properties towards oxygen ( $J_{O 2}$ increases about $50 \%-70 \%$ when compared with the formulation without LDHs) and once more this may be assigned to modifications in the paperboard's silica network (formulation (II)—Figure 7).

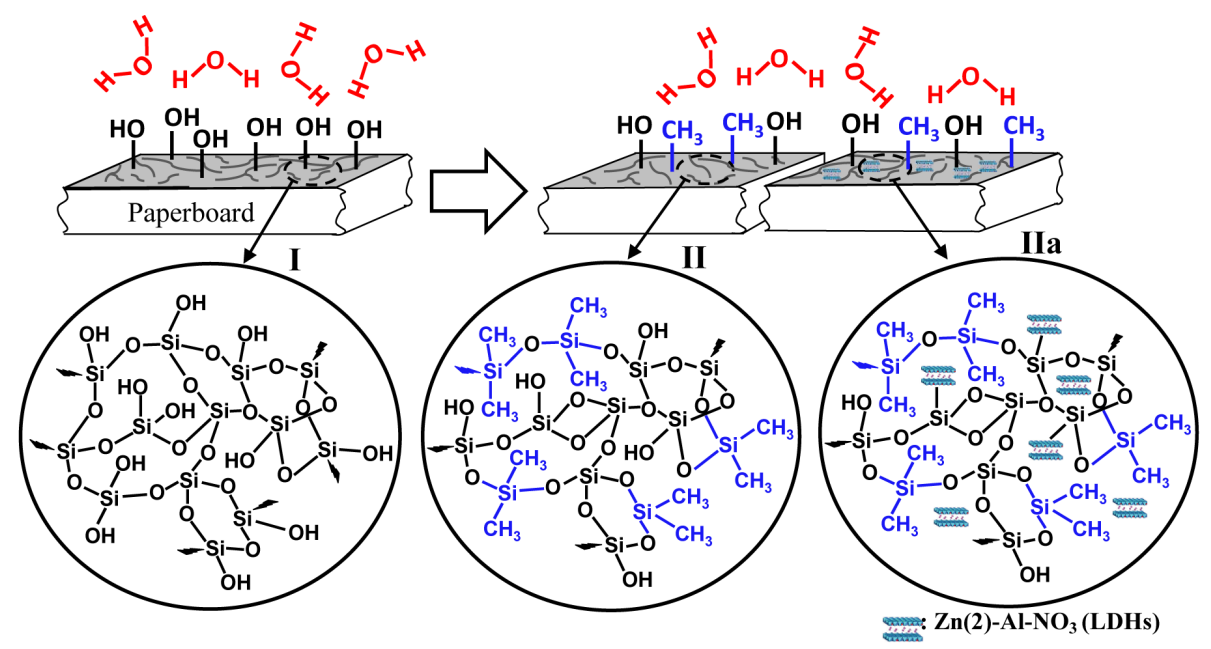

Figure 7. Schematic representation of the interaction of water molecules with the silicanetwork formed on the paperboard surface (TEOS formulation (I), TEOS_DEDMS formulation (II), TEOS_DEDMS formulation with LDHs (IIa)). 


\section{Conclusion}

The results of this study reveal that low grammage $\left(2-3 \mathrm{~g} / \mathrm{m}^{2}\right)$ coating of industrial paperboard with silica formulations prepared with TEOS alone or TEOS $(95 \% \mathrm{v} / \mathrm{v})$ mixed with a co-precursor $(5 \% \mathrm{v} / \mathrm{v}$ of DEDMS, APTES or OTES) is a very promising strategy to impart water and oxygen barrier properties suitable for packaging applications. The addition of high aspect-ratio (flat structure) particles of $\mathrm{Zn}(2)-\mathrm{Al}^{-\mathrm{NO}_{3}}$ (LDHs) to the silica formulation lowers the water vapor transmission rate (WVTR) due to the water scavenging capacity of LDHs and also due to a physical barrier that decreases the vapor diffusivity. The silica modification using co-precursors containing aliphatic moieties decreased both the polar and dispersive components of the surface energy of deposited silica domains conveying water repulsion effects to the paperboard surface. The compilation of these two factors (water repelling functionalities and physical barrier) in specific formulations (TEOS_APTES_LDHs and TEOS_OTES_LDHs) lowered WVTR by nearly $80 \%$ when compared to the "uncoated" paperboard. However, the implementation of LDHs and bulky aliphatic functionalities in silica formulations deteriorate the oxygen barrier properties of silica coatings. The compromise solution, i.e. TEOS_APTES silica formulation without LDHs, exhibited much lower WVTR and oxygen permeability values than for uncoated paperboard, precisely $60 \%$ and $70 \%$ lower, respectively. The critical point for gas barrier in silica-based coatings was suggested to be the violation of the coating physical integrity i.e. formation of microcrackson the paperboard induced by shrinkage upon the curing process. Further work is required to obtainsilica formulations that provide higher dimensional stability to the silica network.

\section{Acknowledgements}

Authors acknowledge the financial support from NANOBARRIER EU FP7 project (FP7-NMP-2011-LARGE-5, ref. $\mathrm{N}^{\circ}$ 280759) and CICECO-Aveiro Institute of Materials grant financed by FCT (PEst-C/CTM/LA0011/2013). The financial support from the project CICECO-Aveiro Institute of Materials (Ref. FCT UID/CTM/50011/ 2013) is greatly acknowledged. Authors also thank the technical assistance of paperboard mill Prado Karton SA. Dr. João Tedim also thanks FCT for researcher grant IF/00347/2013.

\section{References}

[1] Hirvikorpi, T., Vähä-Nissi, M., Harlin, A. and Karppinen, M. (2010) Comparison of Some Coating Techniques to Fabricate Barrier Layers on Packaging Materials. Thin Solid Films, 518, 5463-5466. http://dx.doi.org/10.1016/j.tsf.2010.04.018

[2] Samyn, P. (2013) Wetting and Hydrophobic Modification of Cellulose Surfaces for Paper Applications. Journal of Materials Science, 48, 6455-6498. http://dx.doi.org/10.1007/s10853-013-7519-y

[3] Rahman, M.S. (2007) Handbook of Food Preservation. 2nd Edition, CRC Press, 479-480. http://dx.doi.org/10.1201/9781420017373

[4] Siracusa, V. (2012) Food Packaging Permeability Behaviour: A Report. International Journal of Polymer Science, 2012, 1-11. http://dx.doi.org/10.1155/2012/302029

[5] Han, J., Salmieri, S., Le Tien, C. and Lacroix, M. (2010) Improvement of Water Barrier Property of Paperboard by Coating Application with Biodegradable Polymers. Journal of agricultural and food chemistry, 58, 3125-3131. http://dx.doi.org/10.1021/jf904443n

[6] Stepien, M., et al. (2012) Surface Chemical Characterization of Nanoparticle Coated Paperboard. Applied Surface Science, 258, 3119-3125. http://dx.doi.org/10.1016/j.apsusc.2011.11.048

[7] Khwaldia, K., Arab-Tehrany, E. and Desobry, S. (2010) Biopolymer Coatings on Paper Packaging Materials. Comprehensive Reviews in Food Science and Food Safety, 9, 82-91. http://dx.doi.org/10.1111/j.1541-4337.2009.00095.X

[8] Farris, S., Unalan, I.U., Introzzi, L., Fuentes-Alventosa, J.M. and Cozzolino, C.A. (2014) Pullulan-Based Films and Coatings for Food Packaging: Present Applications, Emerging Opportunities, and Future Challenges. Journal of Applied Polymer Science, 131, 1-12. http://dx.doi.org/10.1002/app.40539

[9] Schmid, M., et al. (2014) Water Repellence and Oxygen and Water Vapor Barrier of PVOH-Coated Substrates before and after Surface Esterification. Polymers, 6, 2764-2783. http://dx.doi.org/10.3390/polym6112764

[10] Vartiainen, J., Vähä-nissi, M. and Harlin, A. (2014) Biopolymer Films and Coatings in Packaging Applications—A Review of Recent Developments. Materials Sciences and Applications, 5, 708-718. http://dx.doi.org/10.4236/msa.2014.510072

[11] Othman, S.H. (2014) Bio-Nanocomposite Materials for Food Packaging Applications: Types of Biopolymer and Na- 
no-Sized Filler. Agriculture and Agricultural Science Procedia, 2, 296-303. http://dx.doi.org/10.1016/j.aaspro.2014.11.042

[12] Bang, G. and Kim, S.W. (2012) Biodegradable Poly(lactic acid)-Based Hybrid Coating Materials for Food Packaging Films with Gas Barrier Properties. Journal of Industrial and Engineering Chemistry, 18, 1063-1068. http://dx.doi.org/10.1016/j.jiec.2011.12.004

[13] Rahman, I.A. and Padavettan, V. (2012) Synthesis of Silica Nanoparticles by Sol-Gel: Size-Dependent Properties, Surface Modification, and Applications in Silica-Polymer Nanocomposites-A Review. Journal of Nanomaterials, 2012, 1-15. http://dx.doi.org/10.1155/2012/132424

[14] Pandey, S. and Mishra, S.B. (2011) Sol-Gel Derived Organic-Inorganic Hybrid Materials: Synthesis, Characterizations and Applications. Journal of Sol-Gel Science and Technology, 59, 73-94. http://dx.doi.org/10.1007/s10971-011-2465-0

[15] Wang, S.X., Mahlberg, R., Nikkola, J., et al. (2011) Surface Characteristics and Wetting Properties of Sol-Gel Coated Base Paper. Surface and Interface Analysis, 44, 539-547. http://dx.doi.org/10.1002/sia.3841

[16] Wang, S.X., Jämsä, S., Mahlberg, R., et al. (2014) Treatments of Paper Surfaces with Sol-Gel Coatings for Laminated Plywood. Applied Surface Science, 288, 295-303. http://dx.doi.org/10.1016/j.apsusc.2013.10.024

[17] Sequeira, S., Evtuguin, D.V., Portugal, I. and Esculcas, A.P. (2007) Synthesis and Characterisation of Cellulose/Silica Hybrids Obtained by Heteropoly Acid Catalysed Sol-Gel Process. Materials Science and Engineering: C, 27, 172-179. http://dx.doi.org/10.1016/j.msec.2006.04.007

[18] Portugal, I., Dias, V.M., Duarte, R.F. and Evtuguin, D.V. (2010) Hydration of Cellulose/Silica Hybrids Assessed by Sorption Isotherms. Journal of Physical Chemistry B, 114, 4047-4055. http://dx.doi.org/10.1021/jp911270y

[19] Latthe, S.S., Imai, H., Ganesan, V., Kappenstein, C. and Venkateswara Rao, A. (2009) Optically Transparent Superhydrophobic TEOS-Derived Silica Films by Surface Silylation Method. Journal of Sol-Gel Science and Technology, 53, 208-215. http://dx.doi.org/10.1007/s10971-009-2079-y

[20] Purcar, V., Stamatin, I., Cinteza, O., et al. (2012) Fabrication of Hydrophobic and Antireflective Coatings Based on Hybrid Silica Films by Sol-Gel Process. Surface and Coatings Technology, 206, 4449-4454. http://dx.doi.org/10.1016/j.surfcoat.2012.04.094

[21] Parale, V.G., Mahadik, D.B., Mahadik, S.A., et al. (2013) OTES Modified Transparent Dip Coated Silica Coatings. Ceramics International, 39, 835-840. http://dx.doi.org/10.1016/j.ceramint.2012.05.079

[22] Mah, S.K. and Chung, I.J. (1995) Effects of Dimethyldiethoxysilane Addition on Tetraethylorthosilicate Sol-Gel Process. Journal of Non-Crystalline Solids, 183, 252-259. http://dx.doi.org/10.1016/0022-3093(94)00631-8

[23] Zhang, X., Wu, W., Wang, J. and Tian, X. (2008) Direct Synthesis and Characterization of Highly Ordered Functional Mesoporous Silica Thin Films with High Amino-Groups Content. Applied Surface Science, 254, 2893-2899. http://dx.doi.org/10.1016/j.apsusc.2007.10.022

[24] Gamelas, J.A.F., Evtyugina, M.G., Portugal, I. and Evtuguin, D.V. (2012) New Polyoxometalate-Functionalized Cellulosic Fibre/Silica Hybrids for Environmental Applications. RSC Advances, 2, 831-839. http://dx.doi.org/10.1039/C1RA00371B

[25] Gamelas, J.A.F., Evtuguin, D.V. and Esculcas, A.P. (2007) Transition Metal Substituted Polyoxometalates Supported on Amine-Functionalized Silica. Transition Metal Chemistry, 32, 1061-1067. http://dx.doi.org/10.1007/s11243-007-0277-4

[26] Newman, S.P. and Jones, W. (1998) Synthesis, Characterization and Applications of Layered Double Hydroxides Containing Organic Guests. New Journal of Chemistry, 22, 105-115. http://dx.doi.org/10.1039/a708319j

[27] Tedim, J., Kuznetsova, A., Salak, A.N., et al. (2012) Zn-Al Layered Double Hydroxides as Chloride Nanotraps in Active Protective Coatings. Corrosion Science, 55, 1-4. http://dx.doi.org/10.1016/j.corsci.2011.10.003

[28] Uysal, U.I., Cerri, G., Marcuzzo, E., Cozzolino, C.A. and Farris, S. (2014) Nanocomposite Films and Coatings Using Inorganic Nanobuilding Blocks (NBB): Current Applications and Future Opportunities in the Food Packaging Sector. RSC Advances, 4, 29393-29428. http://dx.doi.org/10.1039/C4RA01778A

[29] Azeredo, H., Mattoso, L. and McHugh, T. (2011) Nanocomposites in Food Packaging-A Review Advances. In: Reddy, B., Ed., Diverse Industrial Applications of Nanocomposites, InTech, Rijeka, 57-78.

[30] Poznyak, S.K., Tedim, J., Rodrigues, L.M., et al. (2009) Novel Inorganic Host Layered Double Hydroxides Intercalated with Guest Organic Inhibitors for Anticorrosion Applications. ACS Applied Materials \& Interfaces, 1, $2353-2362$. http://dx.doi.org/10.1021/am900495r

[31] Coiai, S., Scatto, M., Conzatti, L., et al. (2011) Optimization of Organo-Layered Double Hydroxide Dispersion in LDPE-Based Nanocomposites. Polymers for Advanced Technologies, 22, 2285-2294. http://dx.doi.org/10.1002/pat.1759

[32] Owens, D.K. and Wendt, R.C. (1969) Estimation of the Surface Free Energy of Polymers. Journal of Applied Polymer 
Science, 13, 1741-1747. http://dx.doi.org/10.1002/app.1969.070130815

[33] Figueiredo, A.B., Evtuguin, D.V., Monteiro, J., et al. (2011) Structure-Surface Property Relationships of Kraft Papers: Implication on Impregnation with Phenol-Formaldehyde Resin. Industrial Engineering Chemistry Research, 50, 28832890. http://dx.doi.org/10.1021/ie101912h

[34] Janssen, D., De Palma, R., Verlaak, S., Heremans, P. and Dehaen, W. (2006) Static Solvent Contact Angle Measurements, Surface Free Energy and Wettability Determination of Various Self-Assembled Monolayers on Silicon Dioxide. Thin Solid Films, 515, 1433-1438. http://dx.doi.org/10.1016/j.tsf.2006.04.006

[35] ASTM E 95-96 (1995) Standard Test Methods for Water Vapor Transmission of Materials (E96-E95). Annual Books of ASTM Standards, 552, 785-792.

[36] Kovalevsky, A.V., Yaremchenko, A.A., Kolotygin, V.A., et al. (2011) Processing and Oxygen Permeation Studies of Asymmetric Multilayer $\mathrm{Ba}_{0.5} \mathrm{Sr}_{0.5} \mathrm{Co}_{0.8} \mathrm{Fe}_{0.2} \mathrm{O}_{3-\delta}$ Membranes. Journal of Membrane Science, 380, 68-80. http://dx.doi.org/10.1016/j.memsci.2011.06.034

[37] Goel, A., Tulyaganov, D.U., Kharton, V.V., et al. (2007) Effect of BaO Addition on Crystallization, Microstructure, and Properties of Diopside-Ca-Tschermak Clinopyroxene-Based Glass-Ceramics. Journal of the American Ceramic Society, 90, 2236-2244. http://dx.doi.org/10.1111/j.1551-2916.2007.01743.X

[38] Yaremchenko, A.A., Kharton, V.V., Avdeev, M., Shaula, A.L. and Marques, F.M.B. (2007) Oxygen Permeability, Thermal Expansion and Stability of $\mathrm{SrCo}_{0.8} \mathrm{Fe}_{0.2} \mathrm{O}_{3-\delta}-\mathrm{SrAl}_{2} \mathrm{O}_{4}$ Composites. Solid State Ionics, 178, 1205-1217. http://dx.doi.org/10.1016/j.ssi.2007.05.016

[39] Miller, F.A. and Wilkins, C.H. (1952) Infrared Spectra and Characteristic Frequencies of Inorganic Ions. Analytical Chemistry, 24, 1253-1294. http://dx.doi.org/10.1021/ac60068a007

[40] Nalwa, H.S. (2003) Handbook of Organic-Inorganic Hybrid Materials and Nanocomposites: Hybrid Materials. American Scientific Publishers, Valencia, 280-285.

[41] Hsiao, V.K.S., Waldeisen, J.R., Zheng, Y.B., et al. (2007) Aminopropyltriethoxysilane (APTES)-Functionalized Nanoporous Polymeric Gratings: Fabrication and Application in Biosensing. Journal of Materials Chemistry, 17, 48964901. http://dx.doi.org/10.1039/b711200a

[42] Tedim, J., Poznyak, S.K., Kuznetsova, A., et al. (2010) Enhancement of Active Corrosion Protection via Combination of Inhibitor-Loaded Nanocontainers. ACS Applied Materials \& Interfaces, 2, 1528-1535. http://dx.doi.org/10.1021/am100174t

[43] Wu, Z., Xiang, H., Kim, T., Chun, M.S. and Lee, K. (2006) Surface Properties of Submicrometer Silica Spheres Modified with Aminopropyltriethoxysilane and Phenyltriethoxysilane. Journal of Colloid and Interface Science, 304, 119124. http://dx.doi.org/10.1016/j.jcis.2006.08.055

[44] Butt, H., Graf, K. and Kappl, M. (2003) Physics and Chemistry of Interfaces. Wiley-VCH, Weinheim.

[45] Yuan, Y. and Lee, T.R. (2013) Contact Angle and Wetting Properties. In: Bracco, G. and Holst, B., Eds., Surface Science Techniques Springer Series, Surface Sciences, Volume 51, Springer Berlin Heidelberg, Berlin and Heidelberg, 3-34. http://dx.doi.org/10.1007/978-3-642-34243-1

[46] Verplanck, N., Coffinier, Y., Thomy, V. and Boukherroub, R. (2007) Wettability Switching Techniques on Superhydrophobic Surfaces. Nanoscale Research Letters, 2, 577-596. http://dx.doi.org/10.1007/s11671-007-9102-4.

[47] Chen, H., Zhang, F., Fu, S. and Duan, X. (2006) In Situ Microstructure Control of Oriented Layered Double Hydroxide Monolayer Films with Curved Hexagonal Crystals as Superhydrophobic Materials. Advanced Materials, 18, 30893093. http://dx.doi.org/10.1002/adma.200600615

[48] Lee, S., Oh, K.K., Park, S., Kim, J.-S. and Kim, H. (2010) Scratch Resistance and Oxygen Barrier Properties of Acrylate-Based Hybrid Coatings on Polycarbonate Substrate. Korean Journal of Chemical Engineering, 26, 1550-1555. http://dx.doi.org/10.1007/s11814-009-0263-y 